\title{
MAPEAMENTO GEOMORFOLÓGICO PRELIMINAR DA ILHA SEYMOUR, ANTÁRTICA
}

\author{
Mariane Paulina Batalha Roque ${ }^{(a)}$, Caroline Delpupo Souza ${ }^{(b)}$, André Luiz Lopes de Faria ${ }^{(c)}$, \\ Carlos Ernesto Gonçalves Reynaud Schaefer ${ }^{(\mathrm{d})}$

\footnotetext{
(a) Departamento de Economia Rural/ Universidade Federal de Viçosa, marianepr.batalha@ gmail.com

(b) Instituto Federal de Educação, Ciência e Tecnologia de Minas Gerais, Campus Conselheiro Lafaiete, caroline.delpupo@ifmg.edu.com

(c) Departamento de Geografia/ Universidade Federal de Viçosa, andre@ufv.br

(d) Departamento de Solos/ Universidade Federal de Viçosa, carlos.schaefer@ufv.br
}

\section{Eixo: 10. SISTEMAS GEOMORFOLÓGICOS: ESTRUTURA, DINÂMICAS E PROCESSOS}

\begin{abstract}
Resumo/
Esta pesquisa descreve de forma preliminar as principais feições geomorfológicas da Ilha Seymour, Antártica peninsular. Além disso, identifica os principais agentes e processos modeladores da paisagem periglacial da ilha. Foram identificadas doze unidades de relevo. São elas: superfície estrutural de cimeira; superfície estrutural pouco dissecada; superfície estrutural muito dissecada; encosta íngreme; encosta suave associada a processos de solifluxão; planície fluviomarinha; planície de maré; planície fluvioglacial; praias, terraços marinhos e falésias; depósito de tálus; solos com padrões; e lagos. Em Seymour, a relação entre os processos geomorfológicos se mostrou determinada pelas condições climáticas regionais, a ação dos ventos, a influência das oscilações das marés, aos agentes fluviais, a processos de integração e desintegração mecânica das rochas causadas pelo congelamento e descongelamento associados a diferentes variações de temperatura, e, sobretudo ao forte controle geotectônico e geológico sobre a distribuição dos ambientes.
\end{abstract}

Palavras chave: geomorfologia de áreas periglaciais; Antártica; geoformas; mapeamento geomorfológico.

\section{Introdução}

Estudos dedicados à compreensão da gênese e mecanismos de funcionamento dos elementos do meio físico representam importantes fontes de conhecimento para o entendimento das paisagens globais. Por sua vez, as técnicas de sensoriamento remoto e geoprocessamento vem desempenhando papel chave nos estudos de paisagens em regiões remotas do planeta. Essa contribuição se torna especialmente importante para estudos geomorfológicos, já que as geotecnologias cada vez mais oferecem métodos e técnicas para a realização de mapeamentos das formas de relevo terrestre. Mapeamentos geomorfológicos de áreas periglaciais da Antártica são grandes exemplos de produtos provenientes de estudos da paisagem em áreas remotas do planeta, utilizando geotecnologias.

O sensoriamento remoto tem sido utilizado em análises de formas e processos geomorfológicos de ambientes glaciais (Clark, 1997), pois oferecem um conjunto de métodos e ferramentas que são úteis para monitorar a diversidade dos processos envolvidos nestes ambientes (Florenzano, 2009); e podem auxiliar na investigação destes processos e formas, contribuindo para o estudo da dinâmica glacial e periglacial de áreas de difícil acesso. Desta forma, imagens de satélite são recursos imprescindíveis, contudo nem sempre de fácil obtenção para a Antártica. 
XVII Simpósio Brasileiro

de Geografia Fisica Aplicada

I Congresso Nacional

de Geografia Física

\section{OS DESAFIOS DA GEOGRAFIA FÍSICA NA FRONTEIRA DO CONHECIMENTO \\ Instituto de Geociências - Unicamp Campinas - SP \\ 28 de Junho à 02 de Julho de 2017}

Embora os ambientes periglaciais constituam um dos mais importantes componentes da paisagem global, principalmente no que diz respeito a processos regulatórios de água, temperatura e carbono, muitas áreas ainda carecem de estudos geomorfológicos mais detalhados. A Ilha Seymour representa especial importância em estudos de natureza geomorfológica, já que, por estar em uma zona de transição climática entre a Antártica Continental e a Marítima, pesquisas desta natureza podem se tornar um importante instrumento para o monitoramento de mudanças ambientais.

Nesse sentido, esta pesquisa, embora em caráter preliminar, buscou identificar, analisar e mapear as feições geomorfológicas que compõem a paisagem da Ilha Seymour; a partir da integração de informações obtidas por imageamento de satélites e de fotografias, sintetizados sob a forma de produtos cartográficos, gerando subsídios ao gerenciamento ambiental desta área.

\section{2. Área de pesquisa}

A Ilha Seymour localiza-se no extremo nordeste da Península Antártica (Figura 01), em uma região de transição climática entre os domínios da Antártica Marítima e da Continental. De acordo com Nozal et al. (2007), a ilha faz parte do grupo de Ilhas James Ross e localiza-se no norte do Mar de Weddell, a aproximadamente $100 \mathrm{~km}$ da extremidade norte da Península Antártica. Encontra-se ao redor das coordenadas $64^{\circ} 17^{\prime} \mathrm{S}$ latitude e $56^{\circ} 45^{\prime} \mathrm{W}$ longitude; ocupa uma área de aproximadamente $20,5 \mathrm{~km}$ no sentido NE-SW por 9,6 km de largura (Elliot et al., 1975).

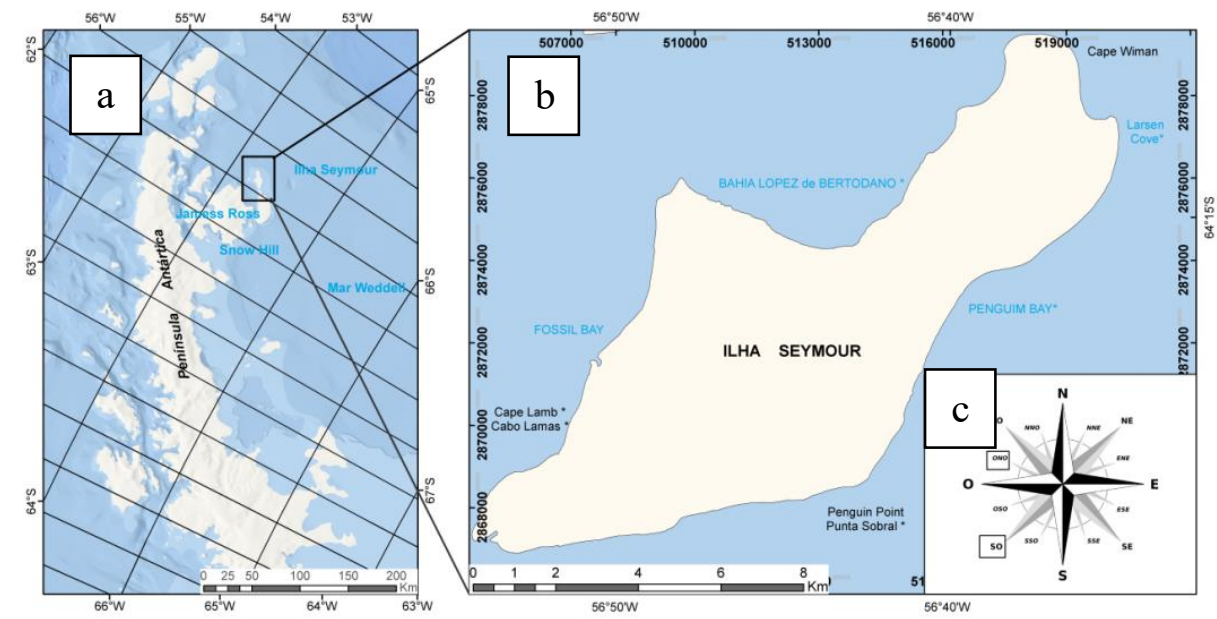

Figura 01: Localização da Ilha Seymour, no contexto da Península Antártica (a); Limites da ilha (b); e direção dos ventos predominantes (c).

\section{Material e Métodos}

A identificação e análise das feições geomorfológicas da ilha Seymour foram realizadas, inicialmente, pela interpretação de fotografias tomadas na visita à área de pesquisa; e posteriormente, pelo auxílio de ferramentas de geoprocessamento. A identificação das formas foi baseada em Glasser et al. (2005), Glasser e Jansson (2005), Hubbart e Glasser, (2005), Smith e Clark (2005), Smith et al. (2006); Gustavsson et al. (2006). A realização da análise dos processos, formas e mapeamentos da Ilha 
Seymour faz parte e dá continuidade aos trabalhos realizados em 2011 durante a OPERANTAR XXIX.

\section{Resultados e Discussão}

\subsection{Aspectos gerais da paisagem: fatores e processos}

A ilha de Seymour constitui uma importante área livre de gelo da Antártica por estar inserido em um setor climático transicional, o que lhe confere um padrão próprio de desenvolvimento de sua paisagem. Seis conjuntos de processos geomorfológicos são responsáveis pela formação das paisagens da ilha. São eles: (i) processos criogenéticos periglaciais; (ii) processos fluviais; (iii) processos lacustres; (iv) processos eólicos; (v) processos marinhos; quase sempre submetidos a um (vi) controle estrutural ou geotectônico. Tais processos atuam quase sempre de forma interativa.

A ilha se situa numa zona de permafrost contínuo e perene (Gutiérrez et al., 2011), embora sua superfície não seja atualmente coberta por geleiras, como seus vizinhos - Ilhas Snow Hill e James Ross. Como no restante da Antártica, durante o inverno, toda a ilha fica permanentemente coberta por neve/gelo; e durante o verão, esta cobertura se torna transitória, condicionada à precipitação nival (Figura 02a, b).

Assim, as ações de processos periglaciais clássicos representam uma importante via modeladora da superfície da ilha. A presença de permafrost e os ciclos de congelamento e descongelamento da camada ativa contribuem para a evolução criogenética de Seymour. Diversas são as evidências destes agentes na ilha. Em cotas mais baixas da paisagem é possível observar diversos afloramentos de domos e cunhas de gelo (Figura 02c, d), provenientes do degelo seletivo do substrato, formando feições de thermokarst.

Em outra porção mais elevada, localizada na base de uma grande superfície protegida, aparece um extenso campo de solos poligonais (Figura 02e, f). Esta feição periglacial consiste no surgimento de padrões na superfície do solo produzidos pela segregação de materiais de diferentes tamanhos como resultados de ciclos de congelamento e descongelamento da camada ativa. Trata-se do processo de crioturbação, bastante típico em solos de diversas regiões da Antártica (Bockheim e Tarnocai, 1998).

Embora os processos periglaciais sejam abundantes, poucas são as evidencias de processos glaciais pretéritos. Um típico vale glacial em $U$, localizado na porção central da ilha, se apresenta como uma feição fóssil que conecta a paisagem periglacial atual de Seymour com um passado de glaciação continental (Figura 02g). Outra evidência glaciogênica que pode ser observada a partir da análise da geologia da ilha, é que a parte culminante da ilha corresponde a uma superfície plana residual, coincidente com depósitos flúvioglaciais de Till da Formação Weddell Sea. Nesse caso, indicando a interação do fator estrutural com seu passado glacial. Possivelmente, estas duas evidências de glaciação continental relacionam-se à mesma época (ultimo máximo glacial). 


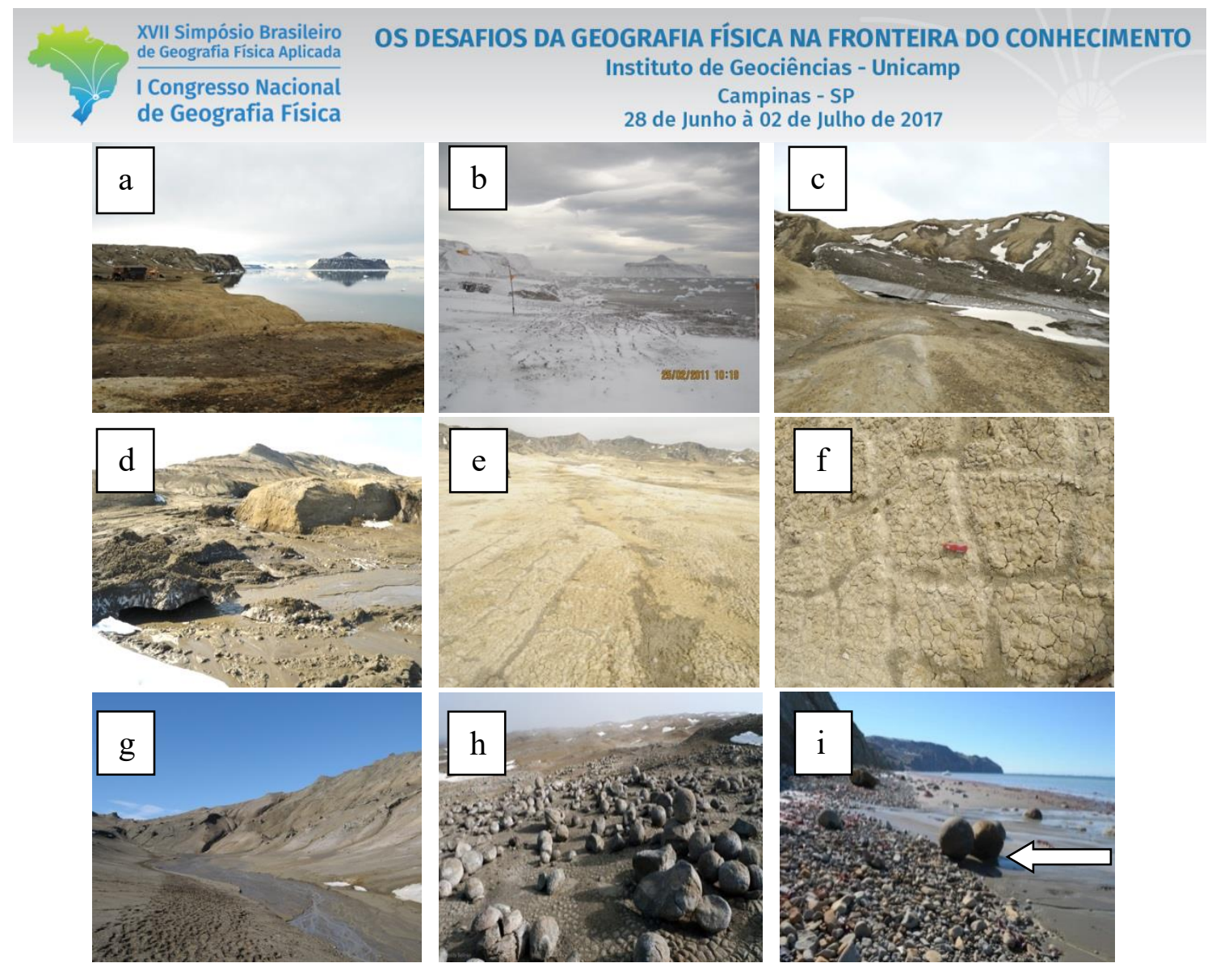

Figura 02: Superfície da ilha antes (a) e depois (b) de uma nevasca. Detalhe da ilha Cock Burn, à direita, nas duas fotografias; Exemplos de cunhas de gelo aflorantes (c) e (d); Solos com padrões, visão geral (e) e nodetalhe (f); Vale glacial fóssil (g); Superfícies da ilha cobertas por clastos de diversos tamanhos (h); mega nódulos formados a partir da exposição da pirita (i).

O sistema de drenagem superficial de Seymour hierarquiza-se segundo a influência de condicionantes sedimentológicos e geotectônico. A partir da análise da drenagem, é possível observar que os cursos d'água de primeira e segunda ordem nascem dos nichos de nivação e possuem um controle basicamente sedimentológico. Por outro lado, as drenagens de terceira ordem e maiores - aquelas que desembocam no mar - possuem um claro controle geotectônico. Gjrup (2013) afirma que os pequenos canais de drenagem sazonais são fruto do impedimento ao livre movimento descendente da água imposto pelo permafrost. Esse processo é responsável por fluxos laterais grandemente favorecidos nas encostas, em função da declividade (Gjrup, 2013). Além disso, o mais desenvolvido curso d'água da ilha está encaixado ao já mencionado vale glacial fóssil da Formação Cross Valley. Esse condicionamento a uma estrutura pré-existente, explica o calado e, principalmente, a largura desse vale, incompatíveis com a dinâmica hidrológica atual.

Parte dos processos fluviais atuantes na ilha é, fundamentalmente, processos flúvioglaciais. Isso porque, a entrada de água líquida se restringe a eventos isolados de precipitação com temperaturas positivas durante o verão. Na maior parte do tempo, a precipitação é nival, que se acumula nas reentrâncias do relevo. Assim, os processos se constituem como flúvioglaciais, haja vista que provém 
principalmente da ação da água de degelo dos neveiros e da fusão da camada ativa. Isso explica o fluxo intermitente do sistema hidrográfico superficial da ilha, notadamente cursos secundários.

De acordo com Souza et al. (2014), o vento é um fator de fundamental importância no processo erosivo e evolução da paisagem em Seymour. O vento participa no transporte, seleção, arredondamento e redistribuição de diversos materiais, notadamente, sedimentos finos, processo responsável pela formação dos pavimentos pedregosos observados em diversas superfícies (Figura 02h). A intensidade de ocupação da superfície por clastos exibe um claro incremento nas porções mais elevadas da ilha. Isso se explica pelo fato da ilha ter sido, no passado, assoalho oceânico que soergueu em diferentes momentos, culminando em diferentes gerações de superfícies soerguidas. Além disso, montículos residuais de erosão eólica são reportados por Souza et al. (2014) na saída do sistema de drenagem principal na porção central da ilha (Figura 02h).

Por sua condição insular, a ação erosiva e deposicional marinha são ativas em todo o perímetro da ilha. Toda a face da ilha voltada para a península é composta por uma extensa plataforma marinha rasa, na verdade, uma planície de maré. Por outro lado, a face voltada para o Mar de Wendell trata-se de uma plataforma marinha profunda, típica de margem de formação tectônica passiva. Como já ressaltado, a ilha representa o produto do soerguimento de antigas plataformas marinhas. A abundância de fósseis encontrados principalmente na Formação La Meseta e Cross Valley; e certa concordância dos topos das plataformas são evidências dessa condição pretérita.

O controle estrutural e tectônico sobre as formas do relevo é evidente, como já mencionado. Em relação ao controle estrutural, Gjorup (2013) notou pontos e cristas proeminentes concordantes com estratos resistentes das rochas. Para esse autor, o controle tectônico também é claro e linhas de falha geralmente limitam compartimentos altimétricos de relevo (Gjorup, 2013).

\subsection{Unidades de relevo da Ilha Seymour}

A ilha possui uma área total de $77 \mathrm{~km}^{2}$, com um gradiente altitudinal brando, com cotas variando do nível do mar até 220 metros de altitude. Tais características fisiográficas relacionam-se ao substrato sedimentar pouco tectonizado da ilha, que lhe conferiu uma paisagem, de forma geral, pouco movimentada e mais tabular.

Podem-se observar três setores com distintas morfologias. O primeiro setor é composto pela superfície estrutural de cimeira - chamada La Meseta - localizado no extremo norte da ilha, atingindo 220 metros de altitude. Ao sul, os terrenos são mais rebaixados com cotas variando do nível do mar até 105 metros de altitude. Por fim, dividindo os outros dois setores, há na porção central da ilha uma área deprimida composta por extensos vales de natureza fluvioglacial.

Doze unidades de relevos foram identificadas e mapeadas na ilha Seymour. São elas: superfície estrutural de cimeira (4,79\%); encostas íngremes (5,4\%); encostas suaves (13,9\%); superfície estrutural muito dissecada (23,2 \%); superfície estrutural pouco dissecada $(21,8 \%)$; planície de maré 
XVII Simpósio Brasileiro

de Geografia Fisica Aplicada

I Congresso Nacional

de Geografia Física
OS DESAFIOS DA GEOGRAFIA FÍSICA NA FRONTEIRA DO CONHECIMENTO

Instituto de Geociências - Unicamp

Campinas - SP

28 de Junho à 02 de Julho de 2017

$(12,1 \%)$; planície fluvioglacial $(0,55 \%)$; planície fluviomarinha $(5,2 \%)$; praias, terraços marinhos e falésias $(1,5 \%)$; deposito de tálus $(1,49 \%)$; solos poligonais $(0,67 \%)$; e lagos $(9,4 \%)$, como mostra a Figura 03.

\subsubsection{Superficie Estrutural de Cimeira}

Localiza-se no ponto culminante da ilha, a $220 \mathrm{~m}$ de altitude, situa-se sob encostas de aproximadamente $200 \mathrm{~m}$, as mais altas observadas em Seymour. Ela corresponde a uma extensa superfície plana e residual. De acordo com Gazdzicki et al. (2004) a origem desta feição está intimamente ligada às ações glaciais ocorridas no passado, com o nivelamento generalizado da paisagem e deposição de material glacial. Uma vez expostos às condições de intemperismo e morfogênese periglaciais subaéreas, diversos setores foram retrabalhados, sendo expostas às litologias subjacentes e originando dois tipos de encostas estruturais. Os estratos resistentes impedem que a dissecação bem desenvolvida das encostas atinja os patamares estruturais, contribuindo para a dissecação incipiente observada na superfície estrutural de cimeira (Figura 04a).

\subsubsection{Encostas Íngremes associadas aos depósitos de tálus}

Localiza-se no entorno da superfície estrutural de cimeira, nas faces mar Weddell e Cape Wiman, fazendo contato entre o topo e as partes mais rebaixadas da paisagem. Tal feição apresenta grande variabilidade altitudinal e declivosa abrangendo cotas de até $200 \mathrm{~m}$ e declividades que oscilam de $45 \%$ até pouco mais de $75 \%$. Este ambiente é constituído por encostas muito íngremes que foram intensamente dissecadas pelo contato com o mar, apresentando consequentemente um forte caráter erosivo (Figura 04b).

A partir do sopé das encostas desenvolve-se um típico depósito de tálus (Figura 03) apresentando-se por blocos rochosos de dimensões variadas; de formato tabular a sub-arredondado. Eles são especialmente frequentes ao longo de toda margem das encostas íngremes que culminam na superfície estrutural de cimeira. Representam superfícies ativas de transportes a curta distância, em que os fragmentos, por ação gravitacional, são transportados encostas abaixo.

\subsubsection{Encostas Suaves}

Tais feições estão localizadas ao sul e também no entorno do grande topo residual da meseta, contrapondo-se às encostas íngremes. Apesar da grande diferença altitudinal apresentada em ambas as feições, a diferenciação das encostas íngremes e suaves se deu, sobretudo, pela declividade (Lee et al., 2002; Vieira e Furtado, 2004). Fato este corrobora com os resultados obtidos (Figura 03) e demonstra que diferentemente das encostas íngremes, a declividade das encostas não ultrapassaram $45 \%$.

A parte norte expõe essa paisagem mais dinâmica, onde existem extensas áreas sujeitas a processos de solifluxão (Figura 03). Assim como descrito por Michel (2005) em estudos na Antártica Marítima, em 
Seymour, os processos de solifluxão na parte norte, tomam destaque quando se tem a combinação da topografia e ações do clima. Para Ostroumov (2004) os locais onde os processos de solifluxão ocorrem estão notadamente relacionados à profundidade dos ciclos de congelamento-descongelamento, o que também pode estar associado com o degelo dos nichos de nivação. Já a parte sul expõe uma paisagem mais estável, onde existem extensas áreas sujeitas às ações desses processos, que aparecem sofrendo forte erosão hídrica, o que corrobora com os estudos de Matsuoka (2001), ao afirmar que a drenagem e a topografia controlam os processos de solifluxão.

Para efeito de mapeamento, este processo foi associado às encostas suaves (Figura 04c). Tomando como base os estudos de Bremer (2008), a solifluxão consiste em um processo de transporte de material, que é dificilmente quantificável na superfície e, por seu tamanho reduzido, esses processos são cartografados apenas quando geram agrupamentos de tamanhos suficientemente grandes.

\subsubsection{Superficies estruturais pouco e muito dissecadas}

As superfícies estruturais pouco e muito dissecadas são as unidades geomorfológicas mais abundantes presentes na ilha. Estas unidades se diferenciam basicamente pela altitude, declividade e dissecação.

As superfícies pouco dissecadas são áreas pouco declivosas com altitudes que variam desde a cota de 25 até 60 m (Figura 04d, e), enquanto que as superfícies estruturais muito dissecadas estão localizados na parte sul da ilha com cotas que variam de 68 até 105 m (Figura 04f, g).

Quanto maior a altitude, mais dissecada e mais ondulada é a paisagem, e isso se justifica pelo fato de que as superfícies mais antigas foram expostas há mais tempo. E que quanto mais próximo das praias, mais recente, e, portanto, menos dissecada é a paisagem - caracterizando as superfícies estruturais pouco dissecadas. Portanto, o nível de dissecação, pouco ou muito, demarca o tempo relativo de exposição dessas áreas.

Essas superfícies pouco dissecadas são sustentadas por estratos resistentes, e nos setores onde a dissecação superou os estratos mais resistentes e expôs o mais friável, é comum a presença de vales, sendo estes, formados, sobretudo pelas condições estruturais do relevo, e a rara ocorrência de afloramentos nestas áreas. 


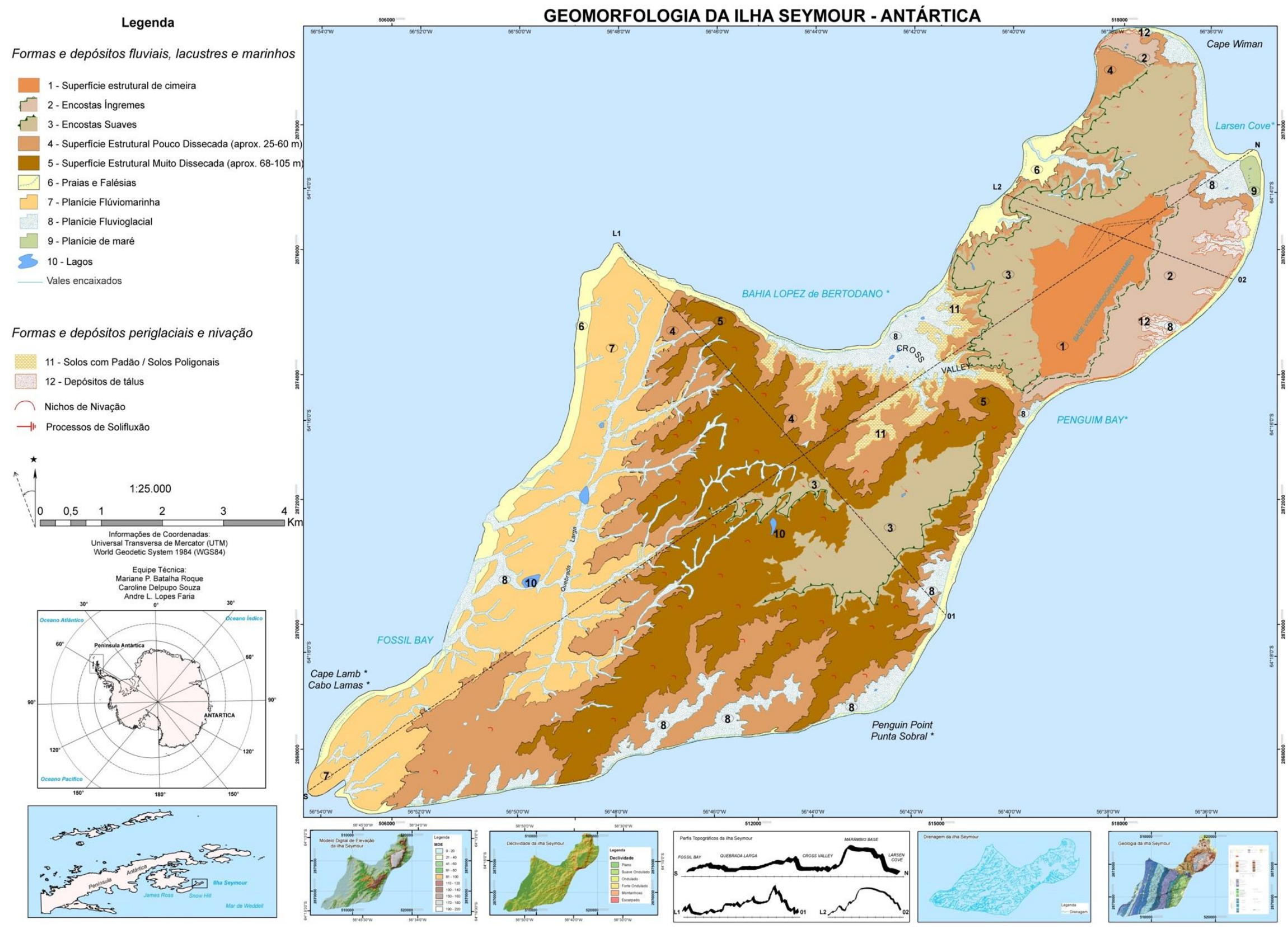

Figura 03: Geomorfologia da ilha Seymour. 

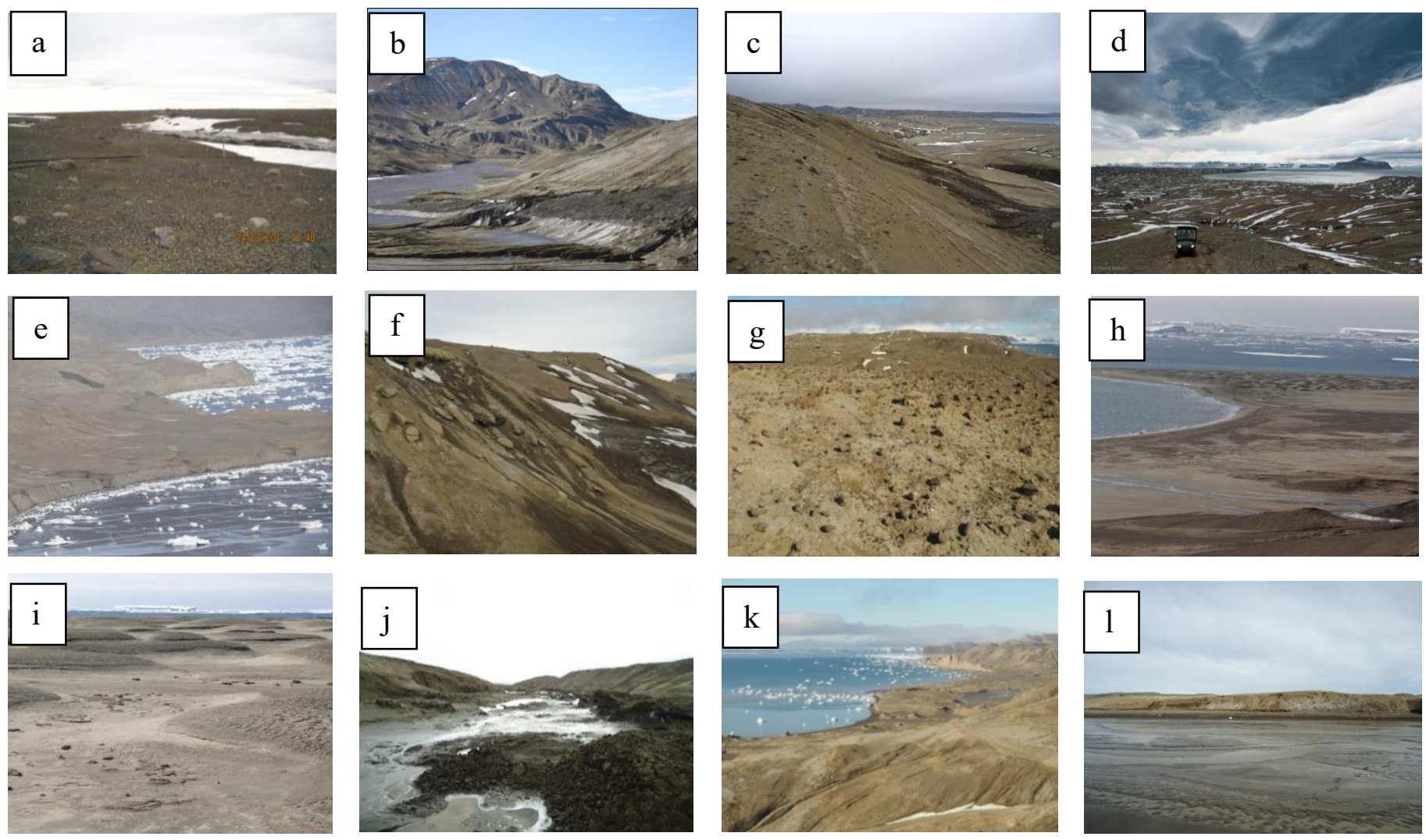

Figura 04: Superfície estrutural de cimeira (a); Encosta íngreme (b); Encosta Suave (c); Superfícies estruturais pouco dissecadas (d) e (e); Superfície estrutural muito dissecada, (f) nichos de nivação e (g) superfície pedregosa; Planície de Maré, (h) Planície de Maré inferior e (i) Planície de Maré superior. Fonte: Gjorup (2013); Planície Fluvioglacial (j); Falésias (k); Planície fluviomarinha (1).

\subsubsection{Planície de Maré}

Esta unidade geomorfológica que se desenvolve na porção norte da ilha (formação La Meseta) é composta por dois níveis altimétricos (Figura 03). A planície de maré inferior (Figura 04h) representa área efetivamente inundável, sujeita ao aporte atual de material marinho. Enquanto a planície de maré superior (Figura 04i) que é composta por elevações isoladas, remodeladas pelo vento. Esta unidade geomorfológica se localiza em cotas que variam desde o nível do mar até aproximadamente $10 \mathrm{~m}$, e apresenta declividade abaixo de $3 \%$.

\subsubsection{Planície Fluvioglacial}

As planícies flúvioglaciais são caracterizadas por baixa declividade, localizando-se nas partes rebaixadas da paisagem, coincidindo com a área de deposição de cursos d'agua, sua localização coincide quase sempre com cotas abaixo de $40 \mathrm{~m}$. Em função da baixa declividade, a ocorrência mais comum dessas 
XVII Simpósio Brasileiro

de Geografia Física Aplicada

I Congresso Nacional

de Geografia Física
OS DESAFIOS DA GEOGRAFIA FÍSICA NA FRONTEIRA DO CONHECIMENTO

Instituto de Geociências - Unicamp

Campinas - SP

28 de Junho à 02 de Julho de 2017

unidades se dá entre as superfícies de soerguimento pouco dissecadas ao sul da ilha (Formação Lopez Bertodano). No entanto, ocorrem planícies inseridas em outros domínios, como em partes deprimidas das encostas íngremes ao norte da (formação La Meseta), fato este observado também por Gjorup, (2013). Esta unidade geomorfológica possui um caráter fortemente deposicional, e está sujeita ao aporte sazonal de sedimentos provenientes das encostas situadas a montante, caracterizando-se por canais anastomosados que transportam e retrabalham sedimentos (Figura 03 e Figura 04j).

Assim como relatado em Byers por Faria (2010), em Seymour os sistemas fluviais são notadamente bem desenvolvidos. Os rios que se localizam sobre as planícies são constituídos por canais anastomosados que mudam constantemente de curso, apresentando uma grande relação ente largura e profundidade. Para Gjorup (2013), o regime hídrico nestes rios é marcadamente sazonal, ocorrendo apenas durante o verão. A principal fonte de alimentação destes rios é o degelo da camada ativa e o derretimento da neve.

\subsubsection{Praias, Terraços Marinhos e Falésias}

As praias de Seymour estão localizadas na linha de costa ao longo de toda a ilha e representam o estágio atual de erosão marinha onde os sedimentos são constantemente remobilizados. Nas praias, há a presença de terraços marinhos, sendo estes compostos principalmente por sedimentos marinhos atuais na porção sul da ilha (formação Lopez Bertodano); sedimentos mais antigos na porção norte (La Meseta); e central das áreas de vales da formação Cross Valley.

Acima das praias observa-se ao longo de toda a costa, linhas de falésias (Figura 04k,), constatou-se que essa unidade geomorfológica na face mar de Weddell são mais abruptas, mais altas, isso esta intimamente relacionada ao fato de que as taxas de soerguimento da borda Weddell ter sido maior, combinado ao fato da agressão da erosão também ser maior. De uma forma ampla, Christofoletti (1980) conceitua as Falésias como "um ressalto, com declividades muito acentuadas e de alturas variadas, localizado na linha de contato entre os terraços e o mar".

De acordo com as pesquisas foi possível perceber que a superfície estrutural foi quebrada, onde o relevo dessas falésias coincide com a morfologia do terreno para trás. Partindo desse pressuposto, acredita-se que no passado deva ter tido uma linha de dique, fraqueza ou mesmo uma zona de cisalhamento de falhas que facilitou tal processo. Desta forma, quando houve o soerguimento que expôs Seymour, a mesma já soergueu desta forma.

\subsubsection{Planície fluviomarinha}

Entre a praia e os diferentes níveis de terraços marinhos na parte sul da ilha sobre a formação Lopez Bertodano, foi mapeado as planícies fluviomarinha (Figura 03). Localizadas em áreas com cotas menores 


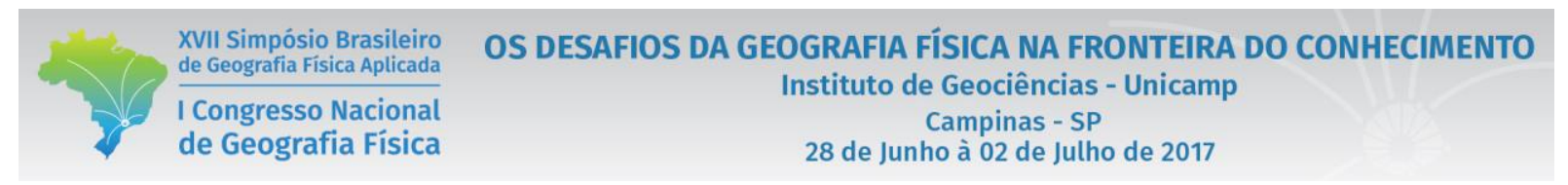

que $22 \mathrm{~m}$, são áreas de grande influência das oscilações das marés e dos processos continentais, com terrenos mal drenados e prolongadamente inundáveis.

Assim como já descrito nos trabalhos de Suguio e Martin (1978), IAC (1999), Maciel (2001) e Amorim (2007) que caracterizam planícies fluviomarinhas em diferentes ambientes sob distintas condições climáticas, em Seymour essa unidade também localiza-se em áreas planas e suavemente onduladas, onde a influência das marés ao longo dos canais fluviais favorece a manutenção de áreas permanentemente alagadas, apresentando desta forma, baixa energia e pequena velocidade de escoamento (Figura 04l).

Em Seymour, a relação entre os processos geomorfológicos se mostrou determinada pelas condições climáticas regionais, a ação dos ventos, a influência das oscilações das marés, aos agentes fluviais, a processos de integração e desintegração mecânica das rochas causadas pelo congelamento e descongelamento associados a diferentes variações de temperaturas e, sobretudo ao forte controle geotectônico e geológico sobre a distribuição dos ambientes.

\section{Conclusão}

A área de pesquisa mostrou grande variabilidade de ambientes representativos de áreas periglaciais situados em uma zona de transição climática entre a Antártica Marítima e a Antártica Continental.

A utilização de geotecnologias mostrou-se bastante útil, gerando resultados satisfatórios perante as formas e processos analisados.

Apesar da natureza exploratória, a pesquisa permitiu avanços em relação aos estudos que já veem sendo feitos no tocante ao entendimento da paisagem de uma importante área livre de gelo, inserida em zona de transição climática entre a Antártica Marítima e Peninsular.

\section{Bibliografia}

AMORIM, R. R. Análise Geoambiental com ênfase aos setores de encosta da área urbana do município de São Vicente-SP. 2007. 194p. (Mestrado em Geografia), Universidade Estadual de Campinas, Campinas. 2007.

BOCKHEIM, J.G.; TARNOCAI, C. Recognition of cryoturbation for classifyingpermafrost-affected soils. Geoderma 81, 281-293 p, 1998.

BREMER, U.F. Solos e geomorfologia da borda leste da península Warszawa, Ilha Rei George, Antártica Marítima. 136 folhas. Tese (Doutorado em Solos e Nutrição de Plantas). Programa de Pós Graduação em Solos e Nutrição de Plantas. Universidade Federal de Viçosa, 2008.

CLARK, C.D. Reconstructing the evolutionary dynamics of former ice sheets using multitemporal evidence, remote sensing and GIS. Quaternary Science Reviews, Oxford, 16, 10671092 p, 1997.

GAZDZICKI, A.; TATUR, A.; HARA, U.; Del VALLE, R.A. The Weddell Sea Formation: post-Late Pliocene terrestrial glacial deposits on Seymour Island, Antarctic Peninsula. Polish Polar Research.v. 25, n. 3-4, p.189-204, 2004. 
FARIA, A,L.L. Solos, geomorfologia e ambientes na parte meridional da Península de Byers, ilha livingston, Antártica Marítima. Viçosa, 2010. 108 p. Tese (Doutorado em Solos e Nutrição de Plantas) - Programa de Pós Graduação em Solos e Nutrição de Plantas. Universidade Federal de Viçosa, 2010.

FLORENZANO, T.G. Geomorfologia: conceitos e tecnologias atuais. São Paulo: Oficina de Textos, 2009. 320p.

GJORUP, D.F. Solos e Geoambientes da porção norte da ilha Seymour (Marambio), Antartica / Viçosa. Dissertação (Mestrado em Solos e Nutrição de Plantas) - Programa de Pós Graduação em Solos e Nutrição de Plantas. Universidade Federal de Viçosa, 2013.

GLASSER, N.F.; JANSSON, K.N.; HARRISON, S.; RIVERA, A. Geomorphological evidence for variations of the North Patagonian Icefield during the Holocene. Geomorphology, 71, p. 263-277, 2005.

GLASSER, N.F.; JANSSON, K.N. Fast-flowing outlet glacier of the Last Glacial Maximum Patagonian Icefield. Quaternary Research, 63, p. 206-211, 2005.

GUSTAVSSON, M.; KOLSTRUP, E.; SEIJMONSBERGEN, A.C. A new symbol-and-GIS based detailed geomorphological mapping system: renewal of a scientific discipline for understanding landscape development. Geomorphology, 77, p. 90$111,2006$.

HUBBARD, B.; GLASSER, N. Field Techniques in Glaciology and Glacial. Geomorphology. Wiley, Chichester UK. 400 p, 2005.

IAC, Instituto Agronômico de Campinas. Mapas Pedológicos do Estado de São Paulo: legenda expandida. Embrapa. Campinas, 1999.

LEE, S.; CHOI, J.; MIN, K. Landslide susceptibility analysis and verification using the Bayesian probability model. Environmental Geology, n. 43, p. 20-131, 2002.

MACIEL, G.C. Zoneamento Geoambiental do município de São Vicente (SP), utilizando o Sistema de Informação Geográfica - SIG. 2001. 150p. (Mestrado em Engenharia Ambiental) Universidade de São Paulo, São Carlos, 2001.

MATSUOKA, N. Solifluction rates, processes and landforms: a global review. Earth-Science Reviews, v. 55, p. 107-134, 2001.

NOZAL, F.; MONTES, M.; SANTILLANA, S.; MARTÍN-SERRANO, A. Unidades del Relieve de la isla Marambio, Antártida. In: VI Argentine and III Latin-American Symposium on Antartic Research. 10 a 14 de setembro de 2007. Dirección Nacional del Antártico/Instituto Antártico Argentino, 2007.

SMITH, M. J.; ROSE, J.; BOOTH, S. Geomorphological mapping of glacial landforms from remotely sensed data: an evaluation of the principal data sources and an assessment of their quality. Geomorphology, 76, 148-165, 2006.

SOUZA, K.K.D.; SCHAEFER.; C.E.G.R.; SIMAS, F.N.B.; SPINOLA, D.N.; PAULA, M.D. Soil formation in Seymour Island, Weddell Sea, Antarctica. Geomorphology 255, 87-99 p, 2014.

SUGUIO, K; MARTIN, L. Mapa geológico: Folha Santos. São Paulo: DAEE/USP/FAPESP. Escala 1:100.000, 1978.

VIEIRA, R.; FURTADO, S. M. A.. Caracterização dos Aspectos Físico-Naturais Intrínsecos da Encosta e Identificação das Áreas Susceptíveis a Deslizamentos na Sub-Bacia do Ribeirão Araranguá -Blumenau/SC. In: Simpósio Brasileiro de Desastres Naturais.1., 2004, Florianópolis. Anais Florianópolis: GEDN/UFSC, p.337-351 p, 2004.

ZINSMEISTER W.J.; VRIES, T. Quaternary glacial marine deposits on Seymour Island. Antarctic Journal of the United States, 18: 64-65 p, 1983 